\title{
Diagnóstico e hierarQuização de PROBlemas de dRenAgem URBana da zona costeira sul do estado da PaRaíba
}

\section{DIAGNOSIS AND HIERARCHIZATION OF URBAN DRAINAGE PROBLEMS IN THE SOUTH COAST ZONE OF PARaíba STATE}

\section{TARCISO CABRAL DA SILVA}

Engenheiro Civil. Doutor em Engenharia Hidráulica. Professor Titular da Universidade Federal da Paraíba - UFPB

\section{Maria Betania Matos de CarValho}

Arquiteta e Urbanista da Superintendência de Administração do Meio Ambiente do Estado da Paraíba - SUDEMA

\section{CARMEM LÚCIA MoReira GadelHa}

Engenheira Civil, Doutora em Engenharia Hidráulica. Professora Adjunta da UFPB - CT

\section{WAMBERTo RAIMUNDO DA SILVA JÚNIOR}

Engenheiro Civil. Mestrando em Engenharia Urbana na UFPB - CT

Recebido: 04/10/06 Aceito: 03/04/08

\section{RESUMO}

A zona costeira do litoral sul do estado da Paraíba é configurada por paisagens diversificadas e caracterizada pela presença de elementos naturais e artificiais que a conferem grande fragilidade e notável beleza cênica. Neste cenário se integram partes de malhas urbanas de municípios litorâneos, áreas de proteção ambiental, falésias, estuários, entre outros. As intervençōes antrópicas que desconsideram a complexidade ambiental destas áreas vêm provocando impactos negativos na paisagem, associados aos problemas de drenagem de águas pluviais. Neste trabalho apresenta-se um diagnóstico, que permitiu a hierarquização dos problemas relativos à drenagem pluvial por orla de cada município inserido nesta zona. Os resultados permitem a tomada de decisão para a escolha de ações visando a atenuação ou eliminação dos problemas identificados.

PALAVRAS CHAVE: Drenagem urbana, diagnóstico, planejamento urbano.

\section{INTRODUÇÃO}

Os espaços litorâneos brasileiros cumprem funções estratégicas nos setores econômicos e na vida social dos estados. O processo de ocupação da zona costeira foi intensificado a partir da década de 60 do século passado. A forma desordenada de produção desses espaços urbanos é agravada sob o ponto de vista ambiental, devido ao alto nível de vulnerabilidade dos ecossistemas costeiros. Atualmente a costa brasileira já apresenta vastas extensões continuamente ocupadas, no interior das quais se encontram aglomerações de expressiva densidade populacional. Na conjunção entre a celeridade e volume dos processos urbanizadores e a fragilidade das áreas envolvidas define-se a premência da ação planejadora na zona costeira, seja o planejamento preventivo nas áreas ainda sem ocupação ou corretivo que busque soluções para os problemas já existentes (Moraes, 1999).

A zona costeira do litoral Sul do Estado da Paraíba é configurada por paisagens diversificadas e caracterizadas pela presença de elementos naturais e artificiais que conferem a este espaço grande fragilidade e notável beleza cênica (Matos de Carvalho, 1997). Neste cenário se integram malhas urbanas constituídas de pequenas e bucólicas cidades e bairros da capital do Estado da Paraíba, Áreas de Proteção Ambiental, Mata Atlântica e ecossistemas associados, dunas, falésias, estuários de diversos rios, barras, lagoas costeiras, planícies costeiras com terraços marinhos planos e de baixas declividades, terrenos declivosos de encosta, e áreas de tabuleiro com cotas mais altas. Problemas associados à drenagem pluvial, não raro, ocorrem nas orlas urbanizadas, área prioritária de planejamento do programa de desenvolvimento turístico do Estado da Paraíba. 
As orlas marítimas urbanizadas ou em processo de urbanização, segundo a definição do Projeto Orla (MMA/SQA; $\mathrm{MP} / \mathrm{SPU}, 2002 \mathrm{a}$ ), são o objeto deste trabalho que trata da identificação e hierarquização dos problemas relativos à drenagem de águas pluviais.

Utilizou-se para a hierarquização nas diversas unidades da área de planejamento, as denominadas orlas, um instrumento baseado na metodologia de listagens de controle escalares de AIA - Avaliação de Impacto Ambiental (Moreira Dias, 1992). No diagnóstico relativo aos principais problemas decorrentes e associados da drenagem urbana, nas diferentes orlas marítimas da área de planejamento referida no Plano de Desenvolvimento Turístico Integrado Sustentável - PDTIS (SEPLAN/PB, 2004), a zona costeira do litoral Sul do Estado da Paraíba, foram apontados os principais problemas relativos à drenagem urbana, quais sejam: i) Alagamentos freqüentes; ii) Ocorrência de processos erosivos; iii) Poluição das praias por ligaçôes clandestinas de esgotos à rede de drenagem existente; iv) Canalização com impermeabilização de cursos d'água.

\section{METODOLOGIA}

\section{Caracterização da área enfocada}

“...Esta terra, Senhor, parece-me que, da ponta que mais contra o sul vimos, até à outra ponta que contra o norte vem, de que nós deste porto houvemos vista, será tamanha que haverá nela bem vinte ou vinte e cinco léguas de costa. Traz ao longo do mar em algumas partes grandes barreiras, umas vermelhas, e outras brancas; e a terra de cima toda chã e muito cheia de grandes arvoredos. De ponta a ponta é toda praia... muito chã e muito formosa..."

Trecho da carta de Pero Vaz de Caminha a El Rei Dom Manuel, relatando $o$ achamento da terra nova, de $1^{\circ}$ dia de maio de 1500.

As ações antrópicas nos espaços litorâneos têm gerado graves desequilíbrios ambientais ao longo dos anos. Estes ambientes se caracterizam por sua complexidade por sofrerem influências diversas (geológicas, climáticas, fluviais, biológicas, oceanográficas, cósmicas, entre outras). É também nestas áreas litorâneas que as forças externas ao planeta são mais perceptíveis, a exemplo do movimento diário das marés ocasionado pelo posicionamento da lua.

No decorrer dos períodos Cretácio e Terciário, uma fase intensa de erosão no interior do Nordeste Brasileiro levou à deposição de sedimentos crono-correlatos, que constituíram as formaçôes integrantes dos grupos Paraíba (Arenitos, Margas e Calcários) e Barreiras (Arenitos, Siltitos e Argilas), os quais se estendem desde os limites da faixa litorânea prolongando-se pela plataforma continental atual. As variações do nível do mar durante o período geológico Quaternário, resultante de glaciaçõos intermitentes e de movimentos epirogenéticos, responderam pela erosão litorânea do grupo Barreiras, dando origem às planícies e tabuleiros litorâneos.

As planícies e tabuleiros litorâneos correspondem a inúmeras porções do litoral brasileiro e quase sempre ocupam áreas muito pequenas. Geralmente são localizadas na foz de rios que deságuam no mar, especialmente daqueles de menor porte. Em trechos do litoral do Nordeste Brasileiro, essas pequenas planícies apresentam-se intercaladas nas áreas de maior elevação pela formação Barreiras, esta também de origem sedimentar. Estas áreas planas e baixas vêm sendo completamente ocupadas por edificações (Rufino, 2004).

As áreas elevadas, correspondentes aos tabuleiros e chapadas, dominam maiores extensões. São platôs subhorizontais, com leve declividade no sentido do litoral. Apresentam-se em alguns setores drasticamente dissecados pelo ciclo erosivo, dando origem a vertentes íngremes e vales fortemente encaixados, com acentuado declive nas cabeceiras. Os tabuleiros conseguem, entretanto, chegar até a costa formando aí as denominadas falésias que atingem duas ou até quatro dezenas de metros de altura. Estas áreas elevadas são constituídas pelos sedimentos da Formação Beberibe e do grupo Barreiras. Grande parte das cidades de João Pessoa e da cidade do Conde, este último também com diversas orlas ocupadas ou em processo de ocupação, encontram-se assentes sobre tabuleiros.

$\mathrm{Na}$ interface entre as planícies costeiras e tabuleiros ocorrem as áreas de grande declividade, correspondente às encostas das barreiras. Quando com declive muito elevado são áreas de preservação permanente, conforme a legislação ambiental brasileira, onde comparecem com freqüência fragmentos de Mata Atlântica.

Já as regiōes deprimidas, coincidem com as planícies de inundação de vales maiores com as baixadas litorâneas, representando interrupçōes do relevo elevado e sendo constituídas pelos depósitos mais recentes (aluvióes e depósitos praiais). Nos vales dos rios Paraíba do Norte ao norte da área enfocada e Goiana no extremo sul ocorrem as maiores porções de áreas de planícies costeiras largas. Outros rios de menor porte também são responsáveis por baixadas litorâneas que constituem franja costeiras menores ou estreitas.

A zona costeira Sul do Estado da Paraíba, compreende uma linha de costa de $74,5 \mathrm{~km}$. Abriga os municípios de Cabedelo ao norte, João Pessoa, Conde e Pitimbu, este último no extremo sul do estado da Paraíba. Limita-se ao sul com o estado de Pernambuco no estuário do rio Goiana, e ao norte, com o estuário do Rio Paraíba do Norte. O município de João Pessoa, capital do Estado, possui a particularidade de abrigar o ponto mais oriental das Américas na praia do Seixas.

A precipitação média anual nesta área é de aproximadamente $1.700 \mathrm{~mm}$ e a evaporação média anual em tanque classe A na Estação Climatológica de João Pessoa é de $1.310 \mathrm{~mm}$. Seu clima pode ser classificado como tropical úmido, apresentando verão seco, sendo a variação de temperatura média mensal do ar ao longo do ano praticamente desprezível. A temperatura média anual é de $26,1^{\circ} \mathrm{C}$.

A área apresenta um índice de urbanização bastante variado, passando pela presença de orlas ainda não ocupadas ou com ocupaçóes intensas como nos municípios de João Pessoa e Cabedelo, este último, com orlas totalmente ocupadas. As áreas não urbanizadas correspondem praticamente a áreas de preservação (porçōes de mata atlântica, manguezais, restingas, espelhos d'água, etc.), com uso agrícola (destaque para a cultura da cana de açúcar) e loteamentos ainda não ocupados.

$\mathrm{Na}$ Tabela 1 estão resumidos os valores de área, população, densidade populacional e comprimento de linha de costa dos municípios em que se inserem as orlas analisadas.

A Figura 1 mostra a localização geográfica destes municípios litorâneos onde se situam as planícies costeiras e os tabuleiros costeiros. Na Figura 
Tabela I - Características dos municípios da zona litorânea sul do Estado da Paraíba

\begin{tabular}{ccccc}
\hline Município & $\begin{array}{c}\text { Área } \\
\left(\mathrm{Km}^{2}\right)\end{array}$ & População & $\begin{array}{c}\text { Densidade populacional } \\
\left(\mathrm{hab} / \mathrm{Km}^{2}\right)\end{array}$ & $\begin{array}{c}\text { Linha de costa } \\
(\mathrm{Km})\end{array}$ \\
\hline Cabedelo & 37,3 & 42.832 & $1.149,2$ & 13,2 \\
Conde & 172,9 & 16.413 & 94,9 & 17,6 \\
João Pessoa & 210,5 & 597.934 & $2.839,9$ & 23,9 \\
Pitimbu & 136,0 & 13.927 & 102,4 & 19,8 \\
\hline
\end{tabular}

2 mostra-se uma representação em modelo digital de terreno de trecho compreendido nos municípios de João Pessoa e Cabedelo, onde se visualizam as ocorrências de planície e de tabuleiros costeiros em maiores elevações, cortados pelos vales dos rios. Na Figura 3 consta a localização das diversas orlas estudadas, em imagem de satélite, onde se destacam as áreas urbanizadas nos municípios de Cabedelo e João Pessoa.

\section{A problemática da drenagem urbana na orla marítima urbanizada ou em processo de urbanização}

\section{As planícies costeiras}

Nas planícies costeiras (praias, terraços marinhos planos e baixos) verificase que a baixa declividade dos terrenos, e a ocupação desordenada ou inadequada dos loteamentos são os principais fatores que agravam a situação da drenagem no período chuvoso ou mesmo em períodos isolados de ocorrência de chuvas intensas, prolongando o tempo em que essas áreas permanecem inundadas. Ainda, pode-se citar que os aterros indiscriminados contribuem fortemente para a degradação dos ambientes e o desequilíbrio do sistema natural de drenagem, redirecionando as águas para outros sítios que passam a ficar também alagados. Neste contexto, outros problemas são associados como a formação de voçorocas, destruição de aterros de vias públicas, alagamento de edificações, etc.

Com efeito, em quase todas as orlas praieiras do litoral do Nordeste a ocorrência de alagamentos e outros problemas associados nas planícies costeiras é freqüente. A cada estação chuvosa ou períodos isolados de ocorrência de chuvas intensas, surgem inundações, erosões pluviais, poluição das praias e de suas águas e em conseqüência os impactos derivados, como diminuição do fluxo turístico, queda no movimento do comércio local, entre outros.

Os problemas decorrentes da urbanização de áreas costeiras das cidades brasileiras apresentam certa semelhança entre si, com leves variações de região para região, de acordo com suas especificidades. As questôes de drenagem não fogem à regra. No entanto, a drenagem de áreas planas e costeiras que além de estarem sujeitas aos problemas comuns às outras regiōes, como regime de chuvas, educação ambiental deficiente da população, falta de conscientização dos tomadores de decisão, despreparo de técnicos envolvidos, entre outros, ainda sofrem pela pressão da ocupação dos terrenos marinhos sem a observância das linhas de costa (Nóbrega, 2002).

Uma outra questão referente às áreas costeiras comparece devido à falta de informação dos planejadores

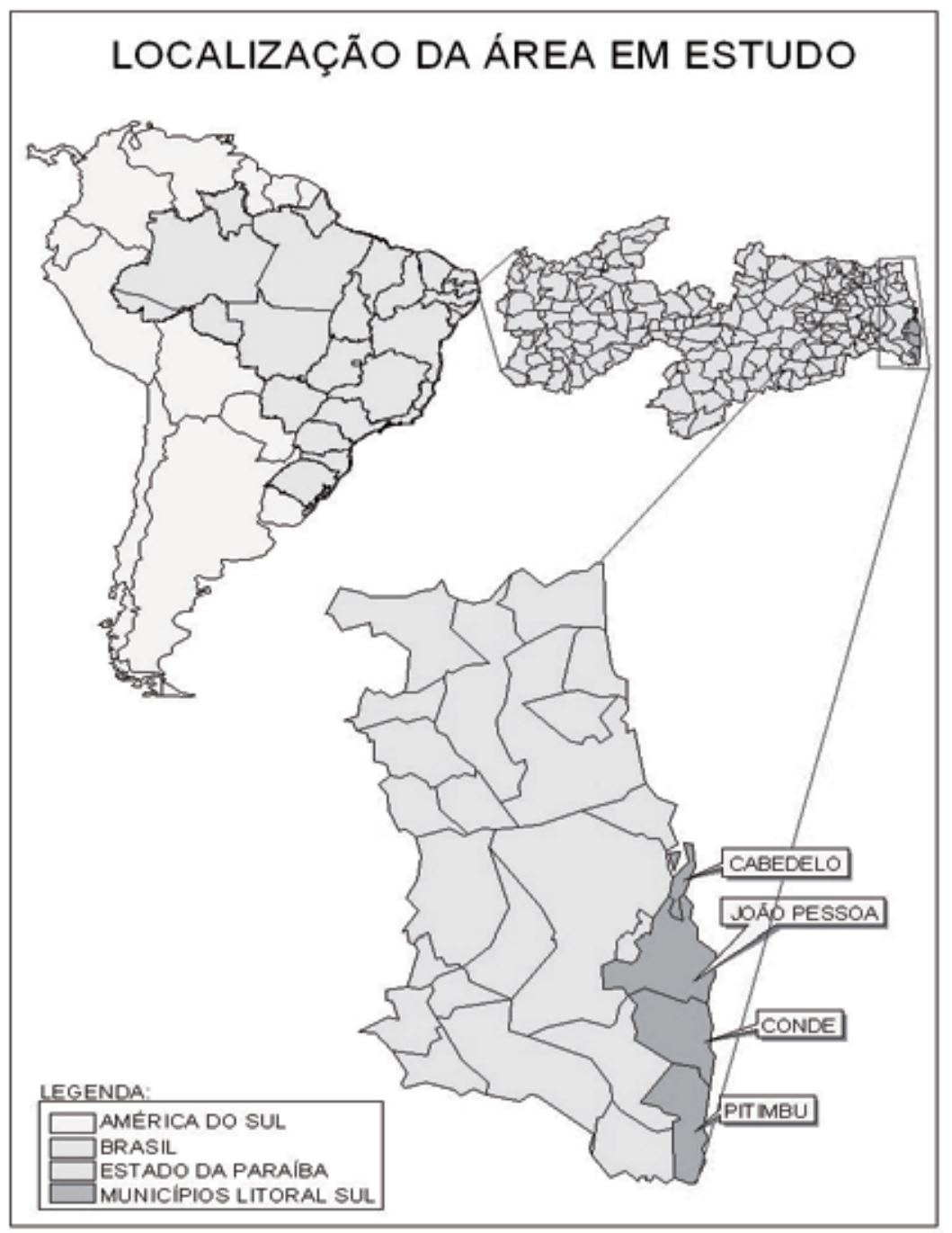

Figura I - Localização dos municípios litorâneos que abrigam as orlas marítimas analisadas 
para a ocupação do solo urbano. Os loteamentos quase sempre são liberados e licenciados sem se considerar os processos que ocorrem na dinâmica marinha. Por exemplo, em João Pessoa na praia do Bessa, os traçados de galerias de águas pluviais passam a acompanhar a ocupação urbana, avançando quase sempre na direção da linha de costa. Tais traçados ficam sujeitos à ação das marés, provocando entre outras conseqüências a obstrução de galerias com areia da praia, o desgaste e gradativa destruição das estruturas hidráulicas de lançamento.

$\mathrm{Na}$ Tabela 2 apresenta-se uma síntese, adaptada de Nóbrega (2002), das características naturais das planícies e tabuleiros costeiros, cenários de diversos problemas de drenagem de águas pluviais.
Mais uma outra preocupação que se coloca nos projetos de sistemas de drenagem que ainda estão sendo implantados atualmente no Brasil é a referente à canalização com impermeabilização de calhas de rios e córregos urbanos, solução adotada para retirar com rapidez do meio urbano a água indesejável. No entanto, para cursos d'água de declividades muito baixas, sujeitos a ação das marés, o escoamento rápido fica prejudicado, provocando o aparecimento de grandes trechos de águas estagnadas. Ademais, estes projetos além de causarem uma série de prejuízos ao meio ambiente por descaracterizar totalmente o habitat natural, iniciam uma cadeia de problemas decorrentes, a exemplo de favorecimento de ligações de esgotos clandestinos, ocupação das margens e das áreas de expansão de cheias e aumento da magnitude das enchentes em áreas a jusante. Outro problema associado decorrente diz respeito ao isolamento da conexão hidráulica entre o curso d'água e o aqüífero: na condição natural o aqüifero seria às vezes influente, às vezes efluente ao rio.

Nos períodos secos ou de pouca pluviosidade, com freqüência, acumulam-se esgotos misturando-se com as águas represadas no álveo do canal impermeabilizado que alcançam tempos de permanência longos. Já que não há neste caso possibilidade de recarga e a conseqüente diluição pelo escoamento básico devido à impermeabilização, são propiciadas as condiçōes para a ocorrência dos fenômenos de eutrofização, proliferação de algas e plantas aquáticas, insetos, mau cheiro e aspecto visual desagradável.

Tabela 2 - Características naturais das planícies e tabuleiros costeiros

\begin{tabular}{ccc}
\hline Características & Planície costeira & Tabuleiro costeiro \\
\hline Tipos de solos & Arenosos & Argilo arenosos \\
Declividade & Muito baixa & Acentuadas \\
Densidade de drenagem & Baixa a média & Média a alta \\
Vegetação & Restinga & Mata costeira \\
Profundidade do lençol freático & Quase aflorante & Relativamente pequena $(>6 \mathrm{~m})$ \\
Cotas em relação ao nível do mar & Baixas & 5 a $40 \mathrm{~m}$ \\
\hline
\end{tabular}

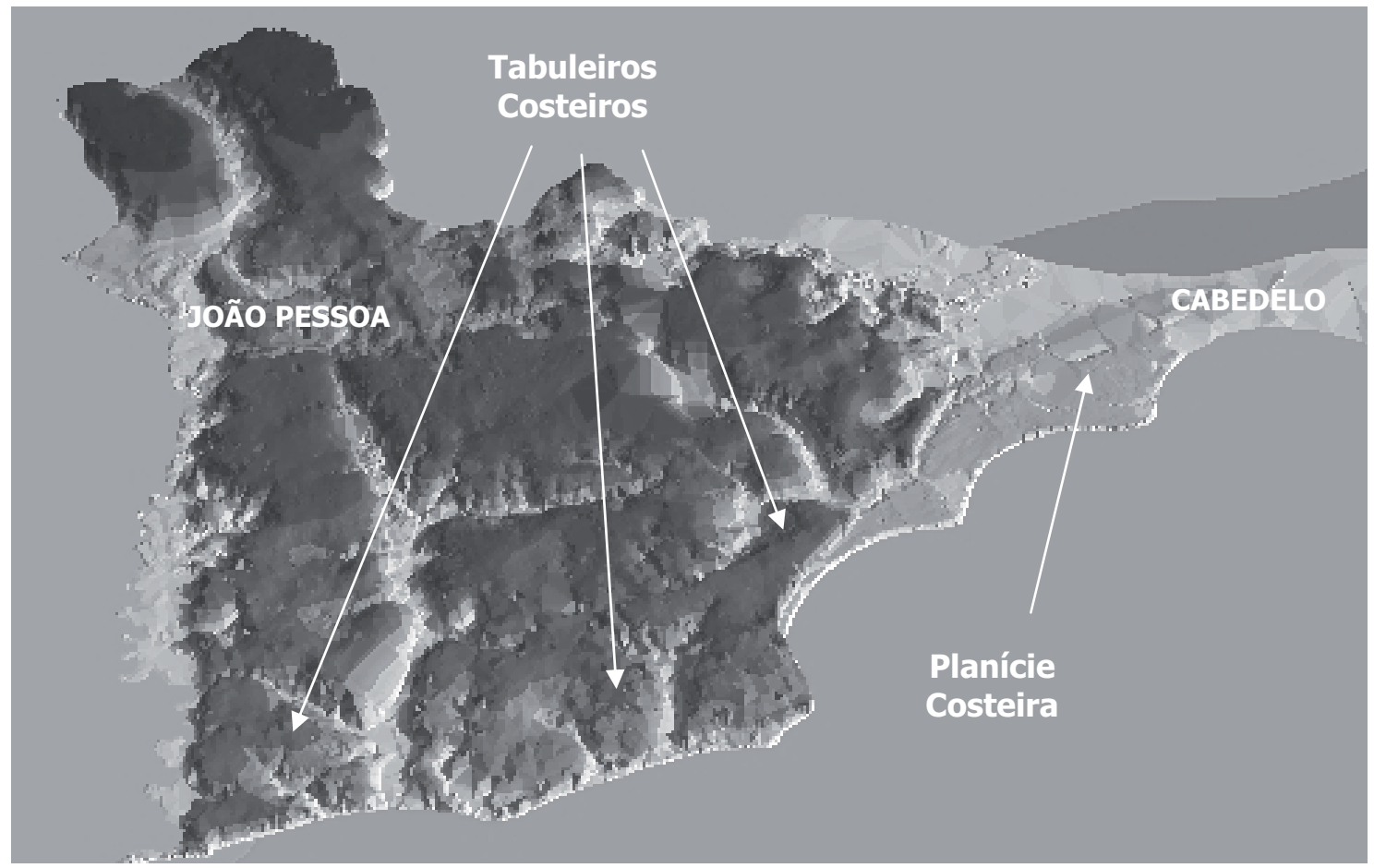

Figura 2 - Modelo digital de elevação da cidade de João Pessoa e parte do município de Cabedelo - PB com destaque para as planícies e tabuleiros costeiros (Rufino, 2004) 


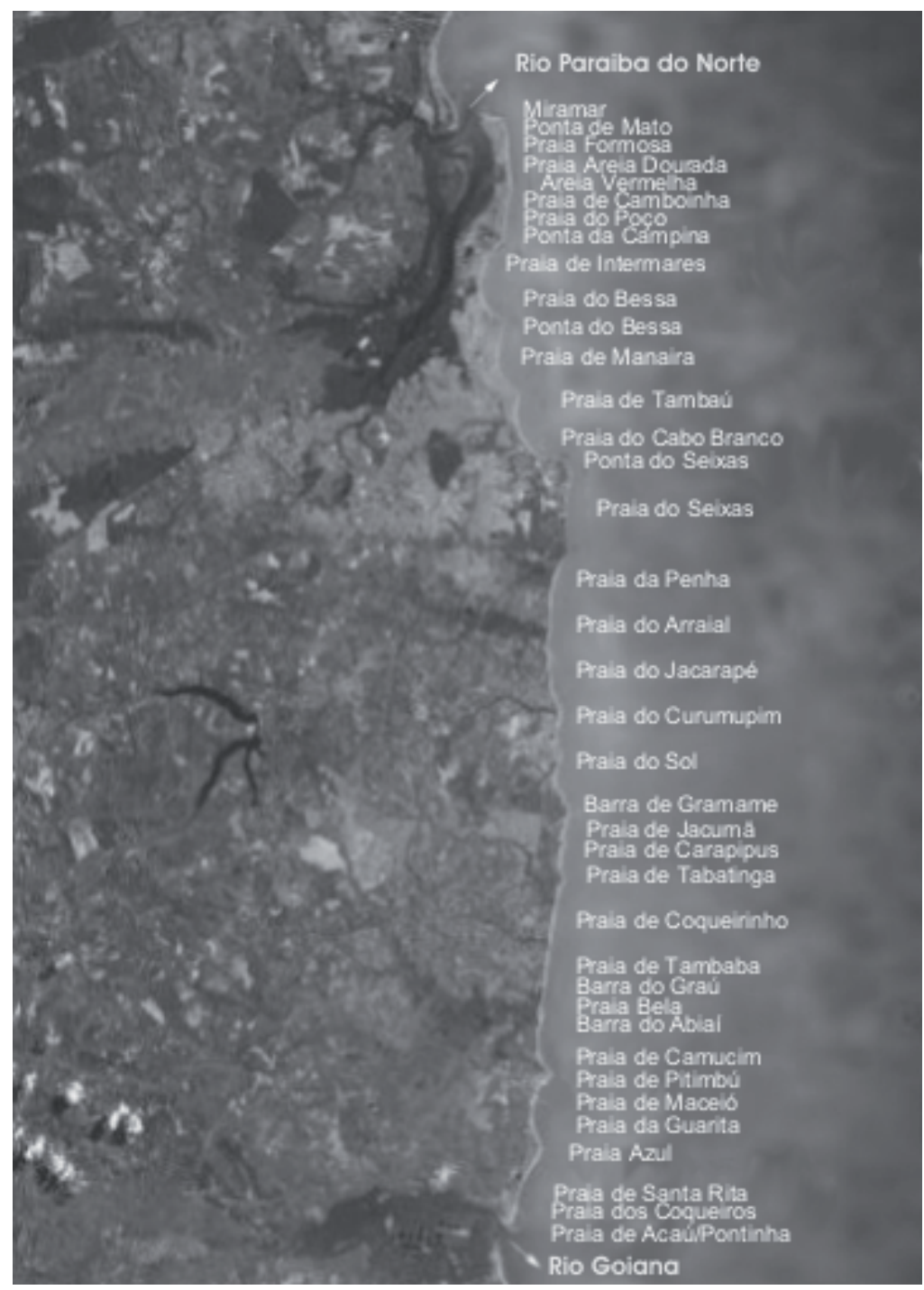

Figura 3 - Localização das diversas orlas analisadas no litoral sul do Estado da Paraíba

\section{Os tabuleiros costeiros}

Nas áreas de tabuleiro, com cotas mais altas (quase sempre acima de cinco até quarenta metros), não são observados problemas significativos advindos do escoamento superficial, haja vista as declividades maiores ou medianas mais freqüentes e a constituição do solo e a vegetação existente que minimizam as possibilidades de acúmulo de água e de erosão. Destaque-se que são áreas geralmente menos ocupadas, talvez devido às dificuldades naturais de acesso às praias. Entretanto, quando ocorre ocupação urbana feita de forma inadequada, com o desmatamento e a execução incorreta de cortes e aterros, aparecem problemas de erosão, com o aparecimento de ravinas e voçorocas.
Os problemas de drenagem de origem antrópica

Nóbrega (2002), após intenso trabalho de revisão bibliográfica e de observação no campo, sintetizou os problemas de drenagem devido à ação antrópica. $\mathrm{Na}$ Tabela 3 apresentam-se os problemas apontados pela autora e observados nas orlas enfocadas com as indicações das possíveis soluções para a atenuação.

\section{O instrumento metodológico utilizado}

Foi utilizado um instrumento metodológico visando a priorização dos problemas, no qual se atribui uma escala de três níveis de relevância:
- nível 1: problema de destaque, significando um importante problema;

- nível 2: problema de importância, mas com destaque menor que o nível anterior;

- nível 3: problema secundário, de pouco destaque ou irrelevante ou inexistente.

Este instrumento, baseado na metodologia de listagens de controle escalares de AIA - Avaliação de Impacto Ambiental (Moreira Dias, 1992), permite diagnosticar os principais problemas decorrentes e associados à drenagem urbana nas diferentes orlas enfocadas. A adoção deste instrumento possibilita ainda a hierarquização das questôes segundo as orlas dos municípios, e torna a tomada de decisões mais eficaz ou oportuna visando a escolha de medidas para a atenuação ou correção dos problemas, principalmente com a possível implantação de Sistemas de Micro e Macrodrenagem - SMMD.

Os principais problemas de drenagem urbanos e associados, identificados através da técnica do Informante Chave (Prestes, 2004) para consideração no diagnóstico foram: Alagamentos freqüientes - AF; Ocorrência de processos erosivos - OPE; Poluição da praia por ligações clandestinas de esgotos à rede de drenagem existente-PPLC; Canalização com impermeabilização de cursos d'água - CICA.

Os tipos genéricos de orla quanto à forma de ocupação, segundo o Ministério do Meio Ambiente (MMA/MP, 2002a), correspondem a: i) orla de urbanização consolidada; ii) orla em processo de urbanização; iii) orla não urbanizada.

\section{RESULTADOS}

Na Tabela 5, mostra-se de forma sistematizada a síntese dos principais problemas relativos à drenagem de águas pluviais com a identificação, em cada orla urbanizada, não urbanizada ou em urbanização na zona costeira, os graus de importância das questôes da drenagem de águas pluviais e problemas associados com seus devidos níveis de destaque.

O diagnóstico resumido na Tabela 5 permitiu a síntese de informaçôes relevantes quanto ao grau de urbanização. Na Tabela 4, apresenta-se o resumo relativo ao estado da orla, por município, concernente à forma de urbanização, segundo a classificação do MMA(MMA/SQA; MP/SPU, 2002b). 
Tabela 3 - Problemas de drenagem devido a ação antrópica

\begin{tabular}{|c|c|c|}
\hline Ação antrópica & Problema & Possíveis soluções/atenuação \\
\hline $\begin{array}{c}\text { • Traçado dos loteamentos } \\
\text { desconsiderando a rede de drenagem } \\
\text { natural }\end{array}$ & - Interrupção do escoamento natural & $\begin{array}{c}\text { - Projetos de loteamentos feitos por } \\
\text { equipe multidisciplinar (NE) } \\
\text { - Obras de drenagem com viés } \\
\text { corretivo (E) }\end{array}$ \\
\hline $\begin{array}{l}\text { - Implantação da rede viária com } \\
\text { represamento da drenagem natural }\end{array}$ & $\begin{array}{l}\text { - Habitações construídas em cotas } \\
\text { abaixo do greid da via }\end{array}$ & $\begin{array}{l}\text { - Implantação da infra-estrutura antes } \\
\text { da ocupação (NE) }\end{array}$ \\
\hline - Ocupação urbana na linha de costa & $\begin{array}{c}\text { - Lançamentos de galerias sujeitos à } \\
\text { ação das marés }\end{array}$ & $\begin{array}{l}\text { - Ordenamento urbano que considere a } \\
\text { dinâmica marinha (NE) }\end{array}$ \\
\hline $\begin{array}{l}\text { - Implantação de drenagem de forma } \\
\text { fragmentada }\end{array}$ & $\begin{array}{l}\text { - Sistemas implantados inadequados e } \\
\text { problemáticos }\end{array}$ & $\begin{array}{l}\text { - Plano Diretor de Drenagem } \\
\text { Urbana (NE) }\end{array}$ \\
\hline - Canalizaçáo de rios e córregos & $\begin{array}{l}\text { • Isolamento do aqüífero; } \\
\text { - Prejuízos ao meio ambiente; } \\
\text { • Enchentes a jusante; } \\
\text { • Favorecimento às ligações } \\
\text { clandestinas de esgoto. }\end{array}$ & $\begin{array}{l}\text { - Restauração de rios canalizados } \\
\text { integrados com os demais planos } \\
\text { municipais (E) }\end{array}$ \\
\hline $\begin{array}{c}\text { - Estações Elevatórias de Esgoto } \\
\text { sem grupo gerador de energia e sem } \\
\text { manutenção, com extravasor ligado } \\
\text { para galeria pluvial }\end{array}$ & $\begin{array}{l}\text { - Poluição das praias que têm } \\
\text { lançamentos de galerias pluviais }\end{array}$ & $\begin{array}{l}\text { - Obrigatoriedade do uso de geradores } \\
\text { nas EEE e manutenção } \\
\text { sistemática (E) e (NE) }\end{array}$ \\
\hline $\begin{array}{c}\text { - Estações Elevatórias de Esgoto } \\
\text { implantadas no Sub-solo dos passeios } \\
\text { públicos }\end{array}$ & $\begin{array}{c}\text { - Dificuldade de identificação da fonte } \\
\text { poluidora nas praias receptoras de } \\
\text { lançamentos de galerias }\end{array}$ & $\begin{array}{c}\text { - Obrigatoriedade de reserva de espaços } \\
\text { destinados às EEE nos loteamentos } \\
\text { aprovados (NE) e (E) }\end{array}$ \\
\hline $\begin{array}{l}- \text { Lixo nas ruas e terrenos baldios } \\
\text { (plásticos, garrafas PET, etc) }\end{array}$ & - Entupimento de galerias e canais. & $\begin{array}{l}\text { - Grelhas nas entradas das } \\
\text { bocas de lobo } \\
\text { - Conscientização da população. } \\
\text { - Eficiência da coleta de lixo (NE) e (E) }\end{array}$ \\
\hline
\end{tabular}

(E) - medidas estruturais; (NE) - medidas não estruturais.

Tabela 4 - Ocorrências por municípios segundo a forma de urbanização

\begin{tabular}{cccc}
\hline Município & Orla não urbanizada & Orla em processo de urbanização & Orla urbanizada \\
\hline Cabedelo & - & - & 8 \\
João Pessoa & 4 & 3 & 4 \\
Conde & 1 & 5 & - \\
Pitimbu & 2 & 7 & 1 \\
\hline
\end{tabular}


Tabela 5 - Síntese dos problemas de drenagem urbana na área de planejamento

Orla

Principais problemas de drenagem urbana e associados

Alagamentos freqüentes - AF; Ocorrência de processos erosivos - OPE; Poluição da praia por ligaçôes clandestinas de esgotos à rede de drenagem existente - PPLC; Canalização com impermeabilização de cursos d'água - CICA

AF OPE PPLC CICA $\Sigma$

\begin{tabular}{|c|c|c|c|c|c|c|}
\hline Miramar $^{1}$ & 1 & 2 & 1 & 1 & 5 & Orla urbanizada, ausência de SMMD \\
\hline Pta. de Matos ${ }^{1}$ & 1 & 3 & 3 & 3 & 10 & Orla urbanizada, ausência de SMMD \\
\hline Formosa $^{1}$ & 1 & 1 & 3 & 3 & 8 & Orla urbanizada, ausência de SMMD \\
\hline Areia Dourada ${ }^{1}$ & 2 & 2 & 3 & 3 & 10 & Orla urbanizada, ausência de SMMD \\
\hline Camboinha $^{1}$ & 1 & 2 & 3 & 3 & 9 & Orla urbanizada, ausência de SMMD \\
\hline Poço ${ }^{1}$ & 1 & 3 & 2 & 3 & 9 & Orla urbanizada, ausência de SMMD \\
\hline Pta. de Campina ${ }^{1}$ & 1 & 3 & 3 & 3 & 10 & Orla urbanizada, ausência de SMMD \\
\hline Intermares $^{1}$ & 1 & 1 & 3 & 3 & 8 & Orla urbanizada, ausência de SMMD \\
\hline Bessa $^{2}$ & 1 & 2 & 3 & 1 & 7 & Orla urbanizada; SMMD parcialmente implantados \\
\hline Manaíra $^{2}$ & 3 & 3 & 1 & 3 & 10 & Orla urbanizada; SMMD implantados \\
\hline Tambaú ${ }^{2}$ & 3 & 3 & 1 & 3 & 10 & Orla urbanizada; SMMD implantados \\
\hline Cabo Branco $^{2}$ & 3 & 2 & 3 & 3 & 11 & Orla urbanizada; SMMD implantados \\
\hline Pta. do Seixas ${ }^{2}$ & 2 & 3 & 3 & 3 & 11 & Orla em processo de urbanização, ausência de SMMD \\
\hline Penha $^{2}$ & 3 & 2 & 2 & 3 & 10 & Orla em processo de urbanização, ausência de SMMD \\
\hline Arraial $^{2}$ & 3 & 3 & 3 & 3 & 12 & Orla não urbanizada \\
\hline Jacarapé $e^{2}$ & 3 & 3 & 3 & 3 & 12 & Orla não urbanizada \\
\hline Camurupim $^{2}$ & 3 & 3 & 3 & 3 & 12 & Orla não urbanizada \\
\hline $\mathrm{Sol}^{2}$ & 3 & 3 & 3 & 3 & 12 & Orla não urbanizada \\
\hline Barra do Gramame ${ }^{2,3}$ & 3 & 2 & 3 & 3 & 11 & Orla em processo de urbanização, SMMD parcialmente implantados \\
\hline Jacumā ${ }^{3}$ & 3 & 2 & 3 & 3 & 11 & $\begin{array}{l}\text { Orla em processo de urbanização; Urbanização fragmentada; } \\
\text { SMMD parcialmente implantados }\end{array}$ \\
\hline Carapibus $^{3}$ & 3 & 1 & 3 & 3 & 10 & Orla em processo de urbanização, ausência de SMMD \\
\hline Tabatinga $^{3}$ & 3 & 1 & 3 & 3 & 10 & Orla em processo de urbanização, ausência de SMMD \\
\hline Coqueirinho $^{3}$ & 3 & 1 & 3 & 3 & 10 & Orla em processo de urbanização, ausência de SMMD \\
\hline Tambaba $^{3}$ & 3 & 1 & 3 & 3 & 10 & Orla não urbanizada \\
\hline Barra do Graú ${ }^{3}$ & 3 & 2 & 3 & 3 & 11 & Orla em processo de urbanização, ausência de SMMD \\
\hline Bela $^{4}$ & 3 & 2 & 3 & 3 & 11 & Orla em processo de urbanização, ausência de SMMD \\
\hline Abiaí $^{4}$ & 3 & 3 & 3 & 3 & 12 & Orla não urbanizada \\
\hline Camucim $^{4}$ & 3 & 3 & 3 & 3 & 12 & Orla não urbanizada \\
\hline Pitimbu $^{4}$ & 1 & 1 & 1 & 2 & 5 & Orla urbanizada, SMMD parcialmente implantados \\
\hline Maceió $^{4}$ & 2 & 2 & 3 & 3 & 10 & Orla em processo de urbanização, ausência de SMMD \\
\hline Guarita $^{4}$ & 3 & 3 & 3 & 3 & 12 & Orla em processo de urbanização, ausência de SMMD \\
\hline $\mathrm{Azul}^{4}$ & 2 & 2 & 3 & 3 & 10 & Orla em processo de urbanização, ausência de SMMD \\
\hline Santa Rita ${ }^{4}$ & 2 & 2 & 2 & 3 & 9 & Orla em processo de urbanização, ausência de SMMD \\
\hline Praia dos Coqueiros ${ }^{4}$ & 3 & 3 & 3 & 3 & 12 & Orla em processo de urbanização, ausência de SMMD \\
\hline Acaú/Pontinha ${ }^{4}$ & 2 & 2 & 2 & 3 & 9 & Orla em processo de urbanização, SMMD parcialmente implantados \\
\hline$\Sigma$ níveis de problemas & 81 & 77 & 93 & 100 & - & \\
\hline
\end{tabular}

Município: ${ }^{1}$ Cabedelo; ${ }^{2}$ João Pessoa; ${ }^{3}$ Conde; ${ }^{4}$ Pitimbu. 
A Tabela 5 permitiu ainda a elaboração da Tabela 6 , onde constam as freqüências relativas observadas dos níveis de relevância dos problemas de drenagem e associados, para as orlas urbanizadas ou em processo de urbanização.

\section{DISCUSSÃO}

$\mathrm{Na}$ área de estudo, as orlas urbanizadas inseridas em planícies costeiras são a maioria e as de maior grau de urbanização, destacando-se as áreas de intensa ocupação nas orlas dos municípios de João Pessoa e Cabedelo.

De acordo com a Tabela 4, o município de Cabedelo apresenta suas 8 orlas já urbanizadas. Quanto aos demais municípios há ocorrência ainda de orlas não urbanizadas, onde obviamente inexistem sistemas de macro e micro drenagem. No entanto, a maioria das orlas dos municípios de João Pessoa, Conde e Pitimbu se encontram em processo de urbanização. Destaque-se ainda a existência de 4 orlas não urbanizadas no município de João Pessoa.

Deduz-se claramente da síntese dos problemas mostrados na Tabela 5 que as orlas compreendendo as áreas urbanizadas dos municípios de Pitimbu e Cabedelo, com destaque respectivamente para as praias de Pitimbu e Miramar ( $\Sigma$ dos níveis de relevância de problemas $=5$ ) são as mais afetadas por problemas associados à drenagem pluvial. Em seguida comparecem as orlas de Bessa no município de João Pessoa; Formosa, Intermares e Poço, em Cabedelo.

É notória a quase ausência de sistemas de macro e microdrenagem de águas pluviais nas orlas analisadas. Foi observado que apenas nas orlas de Tambaú, Manaíra e Cabo Branco, no município de João Pessoa se registra SMMD implantados. Como conseqüência, nestas orlas não se registram problemas de alagamento aparecendo, no entanto, problemas associados.

Os problemas identificados, resumidos na Tabela 6 , relativos à poluição de praias por ligaçóes clandestinas de esgotos à rede de drenagem existente não são significativos, com $72,42 \%$ de freqüência como de nível 3. Da mesma forma, o problema canalização com impermeabilização de cursos d'água também aparece como insignificante. O problema ocorrência de processos erosivos - OPE comparece de maneira mais distribuída, com $72,41 \%$ de

\begin{tabular}{|c|c|c|c|}
\hline \multirow[t]{2}{*}{ Problema } & \multicolumn{3}{|c|}{ Freqüência relativa (\%) } \\
\hline & Nível 1 & Nível 2 & Nível 3 \\
\hline Alagamentos freqüentes & 31,03 & 20,69 & 48,28 \\
\hline Ocorrência de processos erosivos & 24,14 & 48,27 & 27,59 \\
\hline $\begin{array}{l}\text { Poluição da praia por ligaçôes } \\
\text { clandestinas de esgotos à rede de } \\
\text { drenagem existente }\end{array}$ & 13,79 & 13,79 & 72,42 \\
\hline $\begin{array}{l}\text { Canalização com impermeabilização de } \\
\text { cursos d'água }\end{array}$ & 6,90 & 3,45 & 89,65 \\
\hline
\end{tabular}

freqüência para os níveis 1 e 2 . Alagamentos freqüentes comparecem com $51,72 \%$ em níveis 1 e 2 . As presenças de orlas em processo de urbanização ( $42,86 \%$ do total analisado) e aquelas onde já foram implantados os sistemas de micro e macrodrenagem explicam o percentual expressivo de níveis 3 nesta categoria de problema.

No município de João Pessoa, o bairro do Bessa conta com a implantação parcial do sistema de macrodrenagem e uma parcela muito pequena do sistema de microdrenagem. Portanto, são estruturas ainda com cobertura insuficiente para a atenuação a contento de problemas de alagamento que ocorrem com freqüência. Nas orlas de Cabo Branco, Tambaú e Manaíra, que contam com sistemas eficientes de drenagem pluvial não se observam problemas de alagamento ou erosão. No entanto, ligações clandestinas de esgotos ou descargas de estaçōes elevatórias de esgotos - EEE ainda ocorrem nas galerias de drenagem, o que provo-ca eventuais condições indesejáveis de balneabilidade em trechos de praia, principalmente em Tambaú e Manaíra.

As orlas de Carapibus e Tabatinga, no município do Conde, por serem ocupadas em baixios dos tabuleiros costeiros apresentam processos de erosão com ocorrências distribuídas e freqüentes de ravinas e voçorocas, configurando problemas relevantes ao tráfego e à acessibilidade às praias.

\section{CONCLUSÕES}

Ficou patente a carência de implantação de sistemas de macro e microdrenagem de águas pluvias nas orlas analisadas. De fato, apenas nas orlas de Tambaú, Manaíra e Cabo Branco, no município de João Pessoa se registra
SMMD implantados. Como conseqüência, nestas orlas não se registram problemas de alagamento aparecendo, no entanto, problemas associados.

Evidencia-se, à luz do exemplo das orlas de Manaíra, Tambaú e Cabo Branco, no município de João Pessoa, que em áreas já urbanizadas ou em processo de urbanização, os problemas listados em sua maioria seriam corrigidos ou minimizados através da implantação de projetos de drenagem de águas pluviais com apelo corretivo às inadequaçóes do parcelamento do solo porventura ocorridas.

As orlas referentes às áreas urbanizadas dos municípios de Pitimbu e Cabedelo, com destaque respectivamente para as praias de Pitimbu e Miramar foram diagnosticadas como as mais afetadas por problemas associados à drenagem pluvial. Em seguida comparecem as orlas do Bessa no município de João Pessoa; Formosa, Intermares e Poço, em Cabedelo.

A presença de áreas ainda não urbanizadas, com notórias belezas cênicas e valiosos ativos ambientais na zona costeira sul do estado da Paraíba, recomenda a adoção de políticas especiais para o controle da ocupação futura nestas áreas. A repetir-se o padrão de urbanização adotado nos municípios de Cabedelo e João Pessoa, estas características certamente seriam perdidas com prejuízos incalculáveis para a sociedade como um todo.

A metodologia utilizada, ainda que de formato simples, possibilitou o diagnóstico relativo aos problemas decorrentes da drenagem de águas pluviais, permitindo a hierarquização segundo as orlas dos municípios analisados. Torna possível a tomada de decisões mais eficaz ou oportuna para medidas que visem a eliminação ou minimização da problemática identificada. 


\section{REFERÊNCIAS}

DIAS, I.V.M. Origem e Sintese dos Principais Métodos de Avaliação de Impacto Ambiental, Manual de avaliação de Impactos Ambientais MAIA. Paraná, GtZ- SUREHMA, 67p. 1992.

MATOS DE CARVALHO, M.B. Mutaçōes na Paisagem do Litoral Paraibano. São Paulo, FAU/USP. 175f. Dissertação (Mestrado em Arquitetura e Urbanismo). Universidade de São Paulo. São Paulo - SP. Março. 1997.

MMA/SQA; MP/SPU - Ministério do Meio Ambiente/ Secretaria da Qualidade Ambiental; Ministério do Planejamento/ Secretaria do Patrimônio da União. Projeto Orla: manual de gestão. Brasília: MMA/SQA; MP/SPU, 96p. 2002a.

MMA/SQA; MP/SPU - Ministério do Meio Ambiente/ Secretaria da Qualidade Ambiental; Ministério do Planejamento/ Secretaria do Patrimônio da União. Projeto Orla: fundamentos para gestão integrada. Brasília: MMA/SQA; MP/SPU, 78p. 2002 b.

MMA/SQA; MP/SPU - Ministério do Meio Ambiente/ Secretaria da Qualidade Ambiental; Ministério do Planejamento/ Secretaria do Patrimônio da União. Projeto Orla: subsidios para um projeto de gestāo. Brasília: MMA/SQA; MP/SPU, 104p. 2004.

MORAES, A.C.R. Contribuição para a Gestão da Zona Costeira do Brasil: Elementos para uma Geografia do Litoral Brasileiro. São Paulo, Edusp/ Hucitec, 229p. 1999.

NÓBREGA, T.M.Q. A Problemática da Drenagem em Areas Urbanas Planas: O Caso da Planicie Costeira da Cidade de João Pessoa. 129f. Dissertação (Mestrado em Desenvolvimento e Meio Ambiente - PRODEMA). Universidade Federal da Paraíba. João Pessoa - PB. Julho. 2002.

PRESTES, E.M. da T. Aspectos do Envolvimento Público e Técnicas de Previsão e Análise das Tendências dos Processos de Gestão. In: Gerenciamento de Bacias Hidrográficas. UFPB/UFCG/UNESCO, 188p. 2004.

RUFINO, I.A.A. Gestão de Recursos Hídricos em Ambientes Urbanos Costeiros: Modelagem e Representação do conhecimento em sistemas de Informação Geográfica. Tese (Doutorado em Recursos Naturais). Universidade Federal de Campina Grande. Campina Grande - PB. Dezembro. 166f. 2004.

SEPLAN/PB - Secretaria do Planejamento do Estado da Paraíba. PDTIS: Programa de Desenvolvimento Turistico Integrado Sustentável do Pólo Costa das Piscinas. Joāo Pessoa, Paraíba, 990p. 2004.

\section{Endereço para correspondência:}

Tarciso Cabral da Silva

Universidade Federal da Paraíba

- UFPB

Centro de Tecnologia - CT

Cidade Universitária, Campus I,

João Pessoa - PB - Brasil

Telefax (83) 32 I 6-7684

E-mail:tarcisocabral@yahoo.com.br 